\title{
CONFIGURACIÓN ESPACIAL DE LAS AREAS VERDES PÚBLICAS EN EL ÁMBITO DISTRITAL ADYACENTE A LA COSTA VERDE, LIMA
}

\author{
SPATIAL CONFIGURATION OF PUBLIC GREEN SPACES INTO THE ADMINISTRATIVE \\ QUARTERS AT LIMA ALONG COSTA VERDE WATERFRONT
}

\author{
${ }^{1}$ Victor Peña Guillen
}

\begin{abstract}
Resumen
La Costa Verde es el mayor corredor costero de Lima y las áreas verdes al interior tienen posiblemente un potencial de integración con este. El estudio de estos espacios naturales, en el área urbana al interior del frente costero, busca explorar la posibilidad de creación de una red interconectada de parques que mejore la conectividad en el conjunto urbano, considerando el ámbito compuesto por los distritos adyacentes al frente costero. Se sugiere que esta estrategia de conectividad en este ámbito, establece una dimensión integradora y sostenible para el planeamiento y diseño del futuro paisaje de la Costa Verde. Para la representación de las áreas verdes urbanas dentro del tejido urbano, la presente investigación utiliza el modelo de mosaico propuesto por Forman y Godron (1986); este modelo ayuda a visualizar y entender espacialmente al medio urbano a través de componentes llamados fragmentos (parques) y corredores, dentro de una matriz compuesta predominantemente por el mencionado tejido urbano construido. Dispersos en la matriz están los fragmentos correspondientes a las áreas verdes públicas, a los cuales, en la escala utilizada para el estudio, se los observa como unos polígonos con una cobertura homogénea. Estos fragmentos verdes contienen funciones ecológica, a la que concurren plantas y animales, además del medio abiótico que lo sostiene, de modo que lo configura como unos hábitats aislados, con un gran potencial para mejorar las condiciones naturales en la ciudad y el bienestar de la población dentro de su uso recreativo.
\end{abstract}

Palabras Clave: Estructura del Paisaje, Fragmentación, Áreas Verdes Urbanas, Índices de Ecología del Paisaje, Costa Verde.

\begin{abstract}
Abstact
Urban green spaces, located inland the Costa Verde waterfront in Lima and Callao cities, lacks of connection between them and the coastline environment. Costa Verde seaside corridor is the major coastal feature in Lima, and the near public green areas inland have the potential to integrate this waterfront. This study on the configuration of those green patches, aims to visualize the structure of these green areas into the urban matrix. Results show that there is neither, a uniform pattern of park, nor patch distribution onto upper terrace inland. Each administrative quarter shows separate and individual values for the calculated spatial indices. Including the currently isolated patches and considering an area wider than the coastal corridor (driven by its natural function) could enhance connectivity in the whole waterfront landscape; this concept aims to be applied in a comprehensive planning and design of landscape along Costa Verde.
\end{abstract}

Key words: Landscape Structure, Fragmentation, Urban Green Spaces, Landscape Ecology Metrics, Costa Verde Waterfront.

\section{Introducción}

Los espacios verdes estudiados pertenecen a los distritos aledaños al frente costero de la Costa Verde; estos tienen actualmente escasa interconexión entre ellos y también con el frente costero. La Costa Verde es el espacio geográfico correspondiente al litoral costero de la bahía de Lima, ubicado entre dos componentes fisiográficos bien definidos y que corresponderían a la clasificación de penínsulas: el Morro Solar y La Punta. Este espacio costero se caracteriza por la presencia de un acantilado masivo, conformado por material granular de relleno acumulado naturalmente, que define un desnivel promedio de $60 \mathrm{~m}$ entre la línea de playa y la terraza superior donde se asienta la ciudad.

La estructura urbana sobre esa terraza, está compuesta por edificaciones y vías construidas sobre antiguos campos agrícolas, que sufrieron un gran proceso de urbanización a partir de la segunda mitad del siglo XX. Las áreas verdes de acceso público, esparcidas en los distritos aledaños al litoral de la Costa Verde, son los fragmentos naturales remanentes del proceso de urbanización mencionado.

Un concepto que ayuda a visualizar y entender 
espacialmente al medio urbano es observándolo como un mosaico compuesto de fragmentos y corredores (Forman, 1995), dentro de una matriz compuesta predominantemente de elementos construidos. Dispersos en la matriz están los fragmentos correspondientes a las áreas verdes públicas, a los cuales se los modela como unos polígonos con una cobertura homogénea. Este espacio contiene una función ecológica, a la que concurren plantas y animales, de modo que lo configura como un hábitat o biotopo.

Las áreas verdes son un componente importante del paisaje urbano; el valor de estos espacios se debe a los beneficios ambientales, económicos y sociales que proveen, tales como el mantenimiento de la biodiversidad, el incremento en el precio de las propiedades y la mejora de la calidad de vida.

Una forma de mantener la provisión de estos beneficios de manera sostenible en el tiempo, podría considerar como estrategia la integración en una red interconectada de áreas verdes. La interconexión de los parques a través de corredores verdes en la vías permitiría la circulación de los flujos de energía, especies y nutrientes, necesarios para mantener el hábitat natural.

"La distribución y configuración de los biotopos refleja las condiciones para la biodiversidad en las áreas urbanas y pueden ser utilizadas como indicadores para el planeamiento espacial en la escala del paisaje" (Lofvenhaft et al., 2002).

Para comprender la estructura espacial de las áreas verdes públicas se requiere, en primer lugar, visualizar el mosaico urbano, y después identificar cuantitativamente cual es el patrón de la dispersión espacial de los parques o fragmentos en el interior de la matriz urbana; el objetivo es la interconexión de los fragmentos.

"Los índices (espaciales) son útiles para proveer una primera caracterización de un paisaje, porque ellos describen los aspectos de composición y configuración de la estructura del paisaje," (Botequilha y Ahern, 2002).

El estudio de la configuración de estos fragmentos de área verde, en los distritos aledaños a la Costa Verde, tiene como objetivo cuantificar su número, forma, tamaño y proporción, utilizando índices espaciales. Asimismo con el fin de observar su potencial de integración se identifican otros índices que cuantifican el grado de proximidad entre ellos y la facilidad de conectarlos entre sí a través de corredores.

En el presente estudio la cercanía entre los fragmentos proveerá del criterio para unir a los polígonos a través de corredores; el diseño resultante establecerá una red interconectada de fragmentos y corredores especificando los sectores de la red donde se deberían realizar, a través de planes específicos, las acciones de reverdecimiento y plantación a fin de consolidar la estructura espacial así formada.
Objetivo general

Realizar la identificación de la configuración espacial de los parques dentro de la matriz urbana cuyo espacio comprende la jurisdicción de los distritos de Chorrillos, Barranco, Miraflores, San Isidro, Magdalena, La Perla y La Punta, todos los cuales son adyacentes a la Costa Verde.

\section{Objetivos específicos de la investigación}

- Crear una base cartográfica digital de las áreas verdes públicas en el ámbito de estudio.

- Analizar espacialmente la configuración de los parques o fragmentos correspondientes a las áreas verdes.

- Observar las posibilidades de integración de los fragmentos a través de una propuesta de red interconectada de parques y corredores lineales verdes.

\section{Materiales y métodos}

La presente investigación contempla como área de estudio los límites administrativos de ocho distritos aledaños al litoral de la Costa Verde. Estos distritos son: Chorrillos, Barranco, Miraflores, San Isidro, Magdalena del Mar, San Miguel, La Perla y La Punta. El límite geográfico de la Costa Verde está señalado por dos accidentes claramente identificables: el Morro Solar y La Punta. Las coordenadas correspondientes a los extremos del área de estudio son:

El área y la población distrital se muestra en el Gráfico 1 ; en este podemos apreciar que los tres distritos de mayor superficie (San Miguel, Miraflores y San Isidro) ocupan el $65 \%$ de la superficie total del área de estudio. Esta presencia le proporciona, a estos distritos, un peso específico gravitante en el espacio físico, y asimismo se correlaciona seguramente con la cantidad de áreas verdes que aportan estos dentro del área total de estudio. Cabe señalar que para el presente estudio solo se ha considerado un sector del distrito de Chorrillos (sector aledaño a la Costa Verde), de este modo no se tomó en cuenta la totalidad de su superficie distrital, teniendo en cuenta que el distrito es también aledaño a las costas del sector de Villa (al sur del Morro Solar), cuyo ámbito carece de influencia directa en la Costa Verde.

Tabla 1. Superficie y población del área de estudio (Fuente: Censo INEI, 2007).

\begin{tabular}{llll}
\hline Distrito & & $\begin{array}{c}\text { Superficie } \\
\left(\mathrm{m}^{2}\right)\end{array}$ & $\begin{array}{c}\text { Población } \\
(\mathrm{Hab} .)\end{array}$ \\
\hline Chorrillos (solo & sector & 4712305.6 & 286977 \\
Costa Verde) & & 2614369.4 & 33903 \\
Barranco & 9362951.1 & 85035 \\
Miraflores & 9217887.2 & 58056 \\
San Isidro & 3857069.1 & 50764 \\
Magdalena del Mar & 9408349.9 & 129107 \\
San Miguel & 3341179.2 & 61698 \\
La Perla & 606766.4 & 4370 \\
La Punta & & \\
\hline
\end{tabular}


La población asentada en el área de estudio es de 709 710 habitantes, y el mayor porcentaje relativo de esta se ubica en el distrito de San Miguel donde viven 129107 habitantes $(18 \%)$.

Los distritos mencionados se encuentran asentados sobre el gran cono de deyección que conforma el valle del río Rímac. En este sentido el material de cobertura está representado por depósitos aluviales compuestos por limo y arcilla en las capas superficiales y grava, del conglomerado del valle de Rímac, en las capas más profundas.

A partir de la segunda mitad del siglo pasado todo el sector ha sufrido una transformación en el uso del suelo; el anterior uso agrícola, característico de todo el valle de Lima, fue cambiando al uso urbano. Este cambio generó la fragmentación de las áreas verdes cuya superficie fue reduciéndose quedando los remanentes actuales en forma de fragmentos de forma poligonal, dispersos en la nueva matriz urbana del territorio.

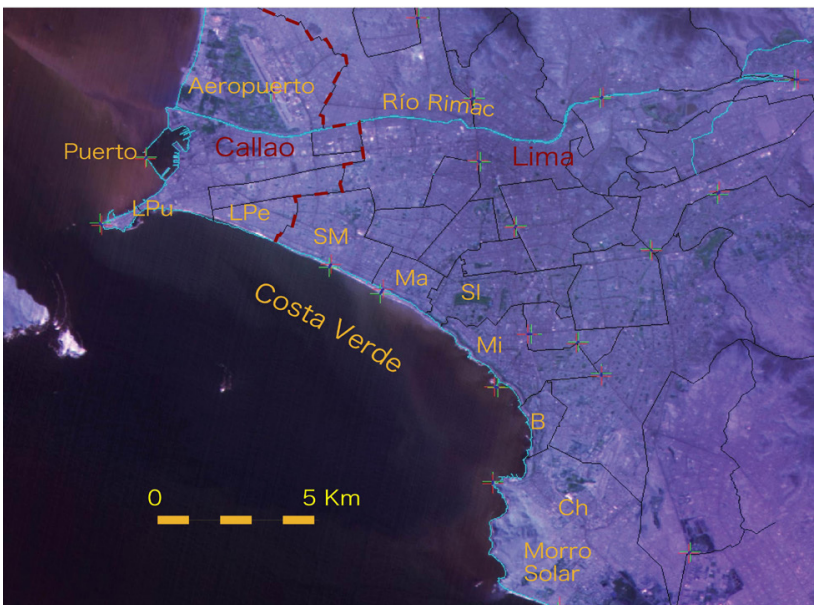

Figura 1. Área de estudio (Fuente: imagen de satélite CBERS).

El enfoque del presente estudio busca la representación de la estructura espacial o configuración de las áreas verdes en el área de estudio dentro de la escala distrital; en este caso se busca identificar un patrón de configuración espacial para el grupo de áreas verdes identificadas en los distritos de la Costa Verde con fines de analizar su conectividad. La disciplina que estudia las relaciones entre el espacio y los procesos ecológicos es la ecología del paisaje. Según Forman y Godron (1986), la ecología del paisaje se enfoca en tres campos: el estudio de los patrones de distribución de los elementos del paisaje, los flujos de animales, plantas, nutrientes, etc., a través de estos elementos, y los cambios ecológicos en el espacio a través del tiempo. El análisis de la distribución espacial de los fragmentos de hábitat representa una de las cuestiones clave de la ecología del paisaje y la aplicación del concepto de red ecológica (Franco, 2003).

Los índices que se analizaran en el presente estudio son tres: tamaño, forma y cantidad de los fragmentos.
De esta manera es necesario recalcar que la referencia bibliográfica señala que existe una correlación entre el tamaño y la abundancia de especies en los fragmentos. En cuanto a la forma, esta nos permite evaluar la integración del polígono con la matriz circundante, en este sentido una forma regular proveerá menos puntos de contacto con el exterior respecto a una forma alargada e irregular. Por otro lado una forma regular proveerá una mayor cantidad relativa de hábitat interior comparado con una forma irregular, favoreciendo esta última a las especies que buscan hábitats de borde o frontera. Finalmente la cantidad de hábitat interior se calcula a partir de los polígonos identificados considerando un buffer de 20 metros hacia el interior, siendo la superficie remanente el área del hábitat interior.

El establecimiento de una red interconectada de áreas verdes considera el criterio de la permeabilidad de la matriz, es decir que tan fácil es la comunicación entre dos fragmentos. La existencia de fragmentos intermedios a distancias cercanas provee un grado de permeabilidad mayor que el caso en los que la distancia entre dos fragmentos es grande en una matriz agresiva como lo es el medio urbano.

La estructura metodológica está basada en la información cartográfica existente para el área de estudio. Asimismo se asume que los parques poseen una función ecológica resultado de sus características naturales, sobretodo suelo permeable y cobertura vegetal. Con estas consideraciones se procede a identificar la configuración espacial de los parques (polígonos o fragmentos) en la matriz urbana.

Una sola clase de cubierta vegetal es evaluada: los parques; para este caso se ha simplificado el análisis estableciendo una sola categoría de cubierta para los parques: la cubierta vegetal, por lo que se asume también una composición uniforme de la cubierta del suelo en los parques.

La identificación de las áreas verdes se basó en dos criterios: parques públicos y bermas con un ancho mayor a $15 \mathrm{~m}$. Una vez identificadas visualmente atraves de las imágenes disponibles en el sitio web Google Earth, se procedió a digitalizar el polígono correspondiente en la base cartográfica utilizando el programa AutoCAD (Autodesk, 2009).

El procesamiento de los datos espaciales fue hecho utilizando dos programas: ArcView 3.2 (ESRI, 1996) y ArcGIS 9.3 (ESRI, 2008).

LA cuantificación de la estructura del paisaje se realizó a través de los índices utilizados en la ecología del paisaje. En el presente estudio se consideran los siguientes índices:

- Porcentaje de área verde (\%).

- Área verde (Ha).

- Área Total del Distrito (Ha).

- Densidad de Fragmentos (Numero de fragmentos /100 Ha). 
- Mediana del Área de los Parques (Ha).

- Mediana del Índice de Forma de los Parques (Ha).

- Número de Fragmentos (fragmentos).

\section{Resultados y discusión}

En primer lugar una vista del mapa de áreas verdes públicas nos muestra un agrupamiento claro, de las áreas verdes distritales, en cuatro sectores separados nítidamente por amplios espacios urbanizados:

1. Chorrillos (Ch).

2. Barranco-Miraflores-San Isidro (B-Mi-SI).

3. Magdalena-San Miguel-La Perla (Ma-SM-LPe).

4. La Punta (LPu).

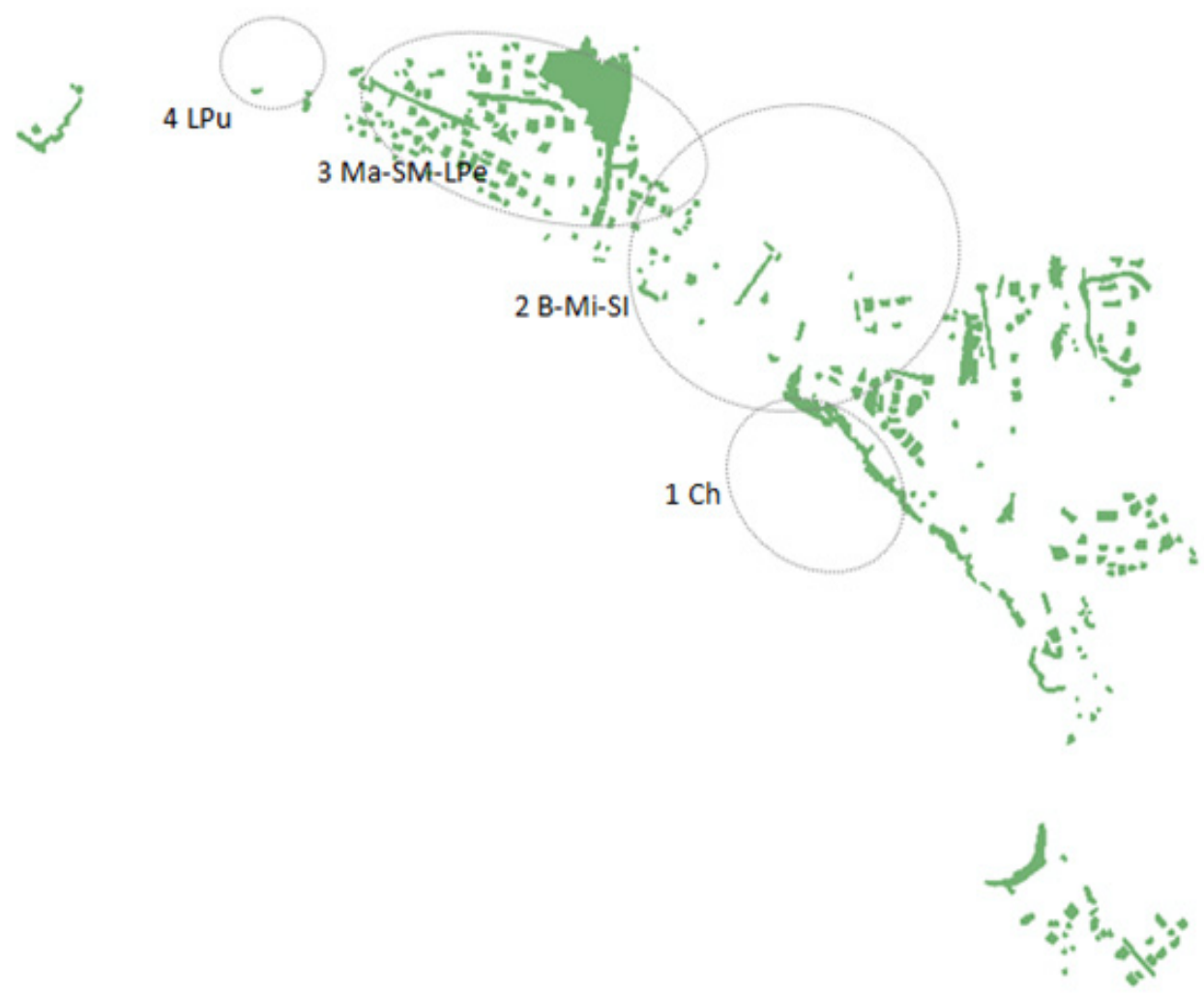

Figura 2. Agrupamiento por sectores en las áreas verdes públicas de los distritos aledaños a la Costa Verde.

Este agrupamiento se resalta más claramente al momento de establecer un área de influencia o buffer de $50 \mathrm{~m}$ a partir del borde externo de cada parque o polígono (Ver Fig. 6); en esta vista se observa una primera alternativa de agrupamiento que puede ser utilizada con fines de gestionar más eficientemente las actividades de mantenimiento de estas áreas.

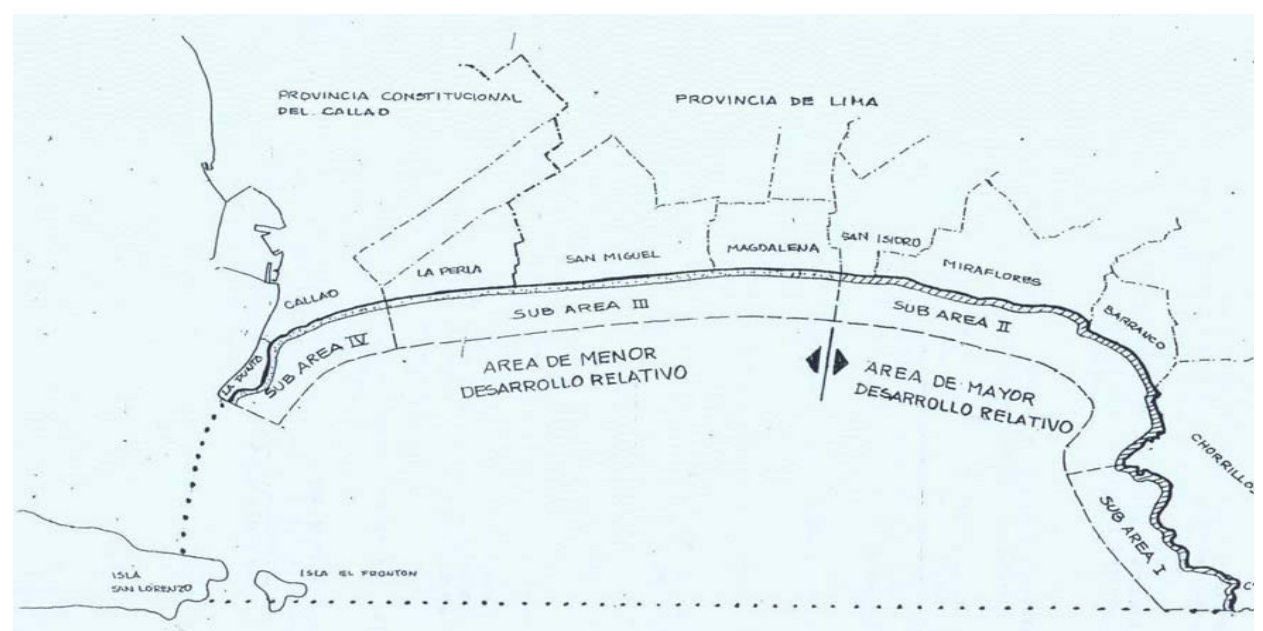

Figura 3. Esquema de Organización espacial de la Costa Verde (Fuente: Plan Maestro 1995-2010). 
En segundo lugar la Fig. 2 muestra discontinuidad y variación en la presencia de los corredores verdes al borde del acantilado. Estos parques lineales son claramente identificables al sur de la bahía (sectores 1 y 2) y pierden conectividad en el sector 3. Cabe señalar que en este último sector se visualiza una mayor densidad de parques localizados a una distancia de $50 \mathrm{~m}$ tierra adentro a partir del borde del acantilado.
$\mathrm{Al}$ respecto al agrupamiento mencionado líneas arriba, este coincide con una sectorización establecida en el "Plan Maestro de la Costa Verde 1995 - 2010", elaborado por la Autoridad Autónoma de la Costa Verde - AACV (ver Fig. 3), donde se indican cuatro sub áreas. Estas sub áreas a su vez se agrupan en dos áreas teniendo en cuenta su desarrollo urbanístico: áreas de mayor y menor desarrollo relativo.

Tabla 2. Resumen de la caracterización espacial de las áreas verdes.

\begin{tabular}{|c|c|c|c|c|c|c|c|c|c|c|}
\hline Indices & 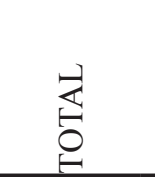 & 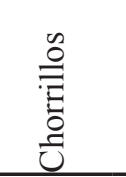 & 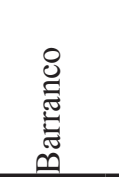 & 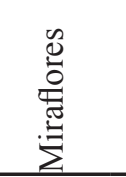 & 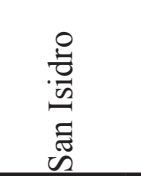 & $\begin{array}{l}\frac{\pi}{\tilde{J}} \\
\frac{\pi}{\pi} \\
\underbrace{0}_{0} \\
\sum\end{array}$ & 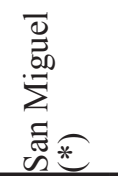 & 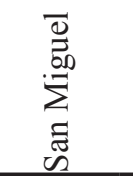 & 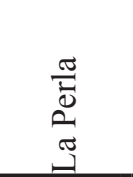 & 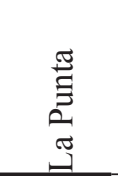 \\
\hline Porcentaje Area Verde (\%) & 5.7 & 5.5 & 2.7 & 5.3 & 7.9 & 2.1 & 16.7 & 6.2 & 5.0 & 9.1 \\
\hline Area Verde Total (ha.) & 244.1 & 26.0 & 7.0 & 50.0 & 72.8 & 8.0 & 156.9 & 58.0 & 16.7 & 5.5 \\
\hline Area Total & 4312.1 & 471.2 & 261.4 & 936.3 & 921.8 & 385.7 & 940.8 & 940.8 & 334.1 & 60.7 \\
\hline $\begin{array}{l}\text { Densidad de Fragmentos } \\
\text { (frag./100 ha.) }\end{array}$ & 11.2 & 8.9 & 8.8 & 5.8 & 19.0 & 4.9 & 12.0 & 11.9 & 15.0 & 13.2 \\
\hline Mediana Area (ha.) & 2661.0 & 2814.3 & 1436.2 & 4083.8 & 1723.3 & 2163.5 & 3746.2 & 3698.8 & 2942.7 & 2866.1 \\
\hline Mediana Indice de Forma (s/u) & 1.3 & 1.2 & 1.3 & 1.2 & 1.3 & 1.3 & 1.2 & 1.2 & 1.2 & 1.4 \\
\hline Numero de Fragmentos (un.) & 483 & 42 & 23 & 54 & 175 & 19 & 113 & 112 & 50 & 8 \\
\hline Longitud Total de Bordes (m) & 149430.3 & 15734.1 & 5821.32 & 23812.6 & 47735.7 & 5447.13 & 38826.3 & 33721.0 & 12806.2 & 4352.3 \\
\hline $\begin{array}{l}\text { Area Verde Per capita (m2/ } \\
\text { Hab.) }\end{array}$ & 5.2 & 5.7 & 2.1 & 5.9 & 12.5 & 1.6 & 12.2 & 4.5 & 2.7 & 12.7 \\
\hline Población (Hab) (**) & 468849 & 45916 & 33903 & 85035 & 58056 & 507641 & 129107 & 129107 & 61698 & 4370 \\
\hline Unidades de Vivienda (un.) & 196125 & 66048 & 10435 & 32902 & 20992 & 14885 & 35054 & 35054 & 14407 & 1402 \\
\hline
\end{tabular}

Hecha la digitalización de las áreas verdes públicas, en la zona de estudio, se identificaron 483 polígonos, los cuales fueron tomados como base para el análisis espacial. El análisis comprende inicialmente el cálculo del área, incluyendo los índices relacionados como el porcentaje de área verde, el área verde per cápita, el índice de forma, la longitud total de los bordes y la densidad de fragmentos.

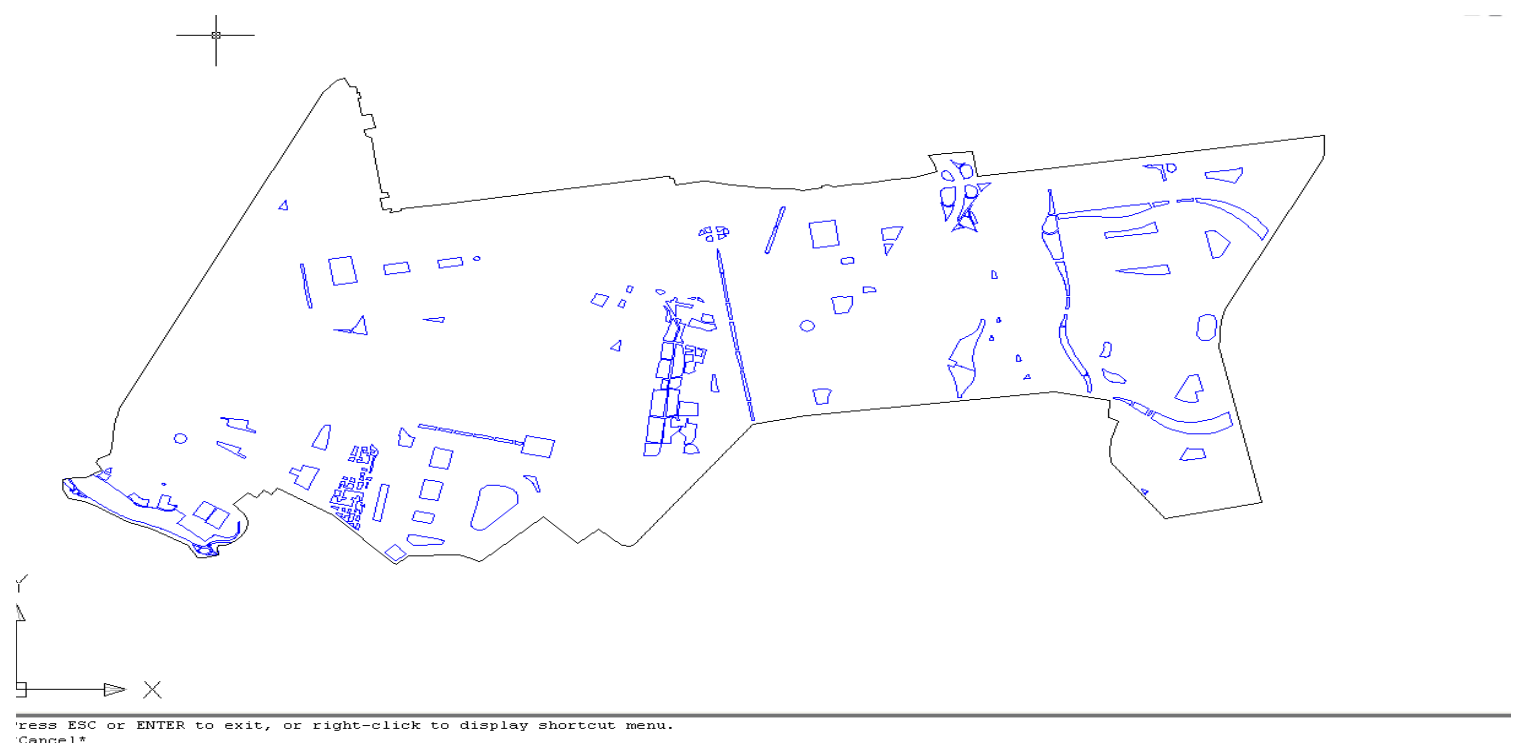

Figura 4. Distribución de las áreas verdes públicas en San Isidro. 


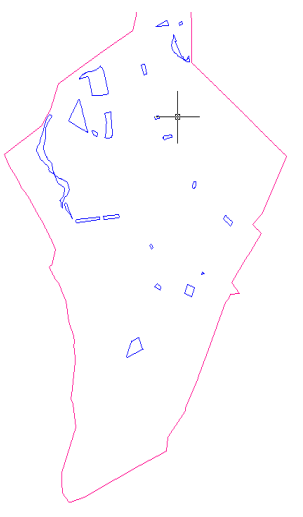

Figura 5. Distribución de las áreas verdes públicas en Barranco.

Todos los índices mencionados son mostrados en el Tabla 2, y proveen un panorama distrital y de conjunto, acerca de la configuración espacial de las áreas verdes públicas. A partir de la información señalada puede advertirse que, en el área de estudio, la superficie de las áreas verdes públicas viene a ser un pequeño porcentaje de la superficie total de la matriz urbana. Comparando los valores a nivel distrital se observa que los distritos de San Miguel (cuando se incluye la superficie del Parque de las Leyendas) y La Punta poseen una porcentaje de áreas verdes mayor al resto de distritos.

También es necesario apuntar el desempeño positivo parejo que tiene el distrito de San Isidro respecto a los valores analizados que, sin llegar al óptimo, muestra una gran densidad de parques (19 unidades/100 Ha) lo que significa un fácil acceso por cercanía; se suma a esto la gran longitud de bordes (47 $736 \mathrm{~m}$ ) lo cual significa que en San Isidro existe un frente amplio de acceso o vista a las áreas verdes. Esto se ve corroborado al observar la configuración espacial en el mapa correspondiente (Ver Fig. 4).

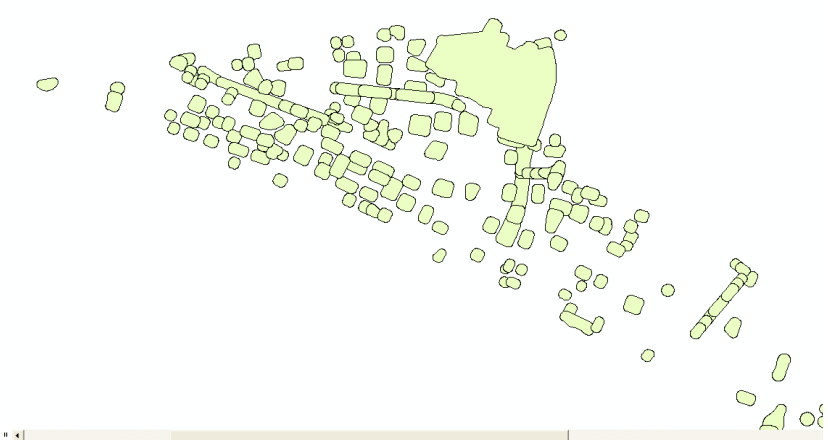

Figura 6. Agrupamiento en el sector 3 (Magdalena-San Miguel-La Perla) con un buffer de $50 \mathrm{~m}$.

En sentido opuesto al de San Isidro, el distrito de Barranco presenta una deficiente proporción de superficie de áreas verdes respecto a la superficie total del distrito. Incluso se nota una distribución desigual que favorece un agrupamiento en el borde del acantilado y una mínima presencia de parques en sectores al interior (ver Fig. 5).

\section{Conclusiones}

La forma de los polígonos correspondientes a las áreas verdes públicas, en general, y los parques, en particular, se aproxima a un rectángulo o un cuadrado, según los valores del índice de forma obtenidos.

El estudio muestra que la configuración espacial de la dispersión de las áreas verdes, en la zona de estudio, no presenta un patrón característico; es decir no se nota un orden en la ocupación del suelo, lo cual se refleja en la falta de proporción y simetría; esto se relaciona con el hecho que el proceso de urbanización en los distritos estudiados no fue el resultado de una plan a escala metropolitana y que mas bien fue resultado de los desarrollos, independientes entre si, propuestos por los promotores inmobiliarios individualmente en cada sector, las iniciativas urbanizadoras que establecieron sus propios patrones sin seguir un modelo predeterminado que permita una mejor integración. Cada emprendimiento urbanístico utilizó un trazo distinto. Un futuro estudio histórico de estas actividades de creación de áreas verdes urbanas en Lima puede ayudar a comprender mejor el fenómeno y condición actual de aislamiento y enfocarse hacia acciones que mejoren y permitan entender el proceso de fragmentación y sugerir una mayor conectividad entre parques.

La mayor conectividad y presencia en los parques lineales al borde del acantilado en el sector sur de la bahía (Chorrillos, Barranco, Miraflores y San Isidro) podría deberse a dos factores: uso ancestral de estas zonas debido a la mayor antigüedad y presencia de asentamientos históricos en estos sectores desde inicios de la República y políticas municipales que favorecen el mantenimiento y uso de estas áreas. En este sentido asentamientos más modernos (urbanizados a mediados del siglo XX) han desarrollado su infraestructura verde de espaldas al mar; esto podría deberse a la inexistencia de playas para uso recreacional y al difícil e inseguro acceso al litoral, durante la etapa de urbanización. La desigual distribución de áreas verdes en el caso especifico del distrito de Barranco se relaciona con el nivel socio-económico, existiendo mayor superficie en los sectores con mayores ingresos económicos. Asimismo se correlaciona con la antigüedad del asentamiento pues en sectores antiguos y de un nivel socio-económico mas alto (viejo balneario) hay mayor superficie de áreas verdes.

\section{Literatura citada}

Ahern, J. 1995. Greenways as a planning strategy: Landscape Urban Planning 33, 131-155.

Autoridad del Proyecto Costa Verde - APCV, 1995. Plan Maestro 1995 - 2010. Documento interno.

Botequilha, A. and Ahern, J. 2002. Applying landscape ecological concepts and metrics in sustainable landscape planning: Landscape Urban Planning 59, 65-93.

Dramstad, WE; Olson, J. E. and Forman, R. T. T. 1996. Landscape Ecology Principles in Landscape Architecture and Land Use Planning. Washington DC. 
Harvard University Graduate School of Design, Island Press, American Society of Landscape Architects. 80 p.

Elkie, P; Rempel, R. and Carr, A. 1999. Patch Analyst User's Manual. Ont. Min. Natur. Resour. Northwest Science and Technology. Thunder Bay, Ontario. 16 p.

Opdam, P. 2005. Ecosystem networks: a spatial concept for integrative research and planning of landscapes. In Tress B.; Tress G.; Fry G. and Opdam P. eds. From Landscape Research to Landscape Planning: Aspects of Integration, Education and Application. p. 51-65.

\section{Agradecimientos}

El presente trabajo de investigación conto con la colaboración de los siguientes alumnos de pre-grado: Paloma Oviedo, Esteban García Arboleda y Franchesco Villar, a quienes se les agradece el apoyo brindado. 